\title{
Radiosensitizing effects of c-myc gene knockdown-induced G2/M phase arrest by intrinsic stimuli via the mitochondrial signaling pathway
}

\author{
YUNPENG FAN $^{1}$, XIAOFENG JIA ${ }^{2}$, TAO XIE ${ }^{3}$, LIULONG ZHU ${ }^{1}$ and FAN HE ${ }^{3}$ \\ ${ }^{1}$ The Affiliated Hangzhou Hospital of Nanjing Medical University, Hangzhou, Zhejiang $310006 ;{ }^{2}$ College of Life Science, \\ China Jiliang University, Hangzhou, Zhejiang $310018 ;{ }^{3}$ Affiliated Hangzhou First People's Hospital, \\ Zhejiang University School of Medicine, Hangzhou, Zhejiang 310006, P.R. China
}

Received June 1, 2020; Accepted September 18, 2020

DOI: 10.3892/or.2020.7806

\begin{abstract}
Osteosarcoma is the most common primary malignant bone tumor in children and adolescents and its long-term survival rate has stagnated in the past decades. Previous studies have shown that tumors in the G2/M phase are more sensitive to radiotherapy. The proto-oncogene c-myc is a transformed member of the myc family and c-myc-interacting zinc finger protein-1 (Miz-1) is a poly-Cys2His2 zinc finger (ZF) activator of cell cycle regulator genes, such as the cyclin-dependent kinase inhibitor $\mathrm{p} 21$. C-myc can repress the expression of $\mathrm{p} 21$ by binding to Miz-1 and abolishing the interaction between Miz-1 and its co-activators, which induces G2/M phase arrest. Therefore, the present study investigated the radiosensitizing effects of the c-myc gene and the sensitizing apoptosis pathway, aiming to identify a more effective combination radiotherapy treatment for osteosarcoma. The present study demonstrated that the c-myc gene was overexpressed in osteosarcoma cells compared to osteoblasts. Following inhibition of c-myc gene expression in osteosarcoma cells, tumor proliferation was significantly hindered after inducing $\mathrm{G} 2 / \mathrm{M}$ phase arrest via regulating $\mathrm{G} 2 / \mathrm{M}$ phase-associated proteins. Additionally, it was revealed that inhibiting c-myc gene expression combined with radiotherapy could significantly increase the apoptosis rate of osteosarcoma cells via the mitochondrial signaling pathway. In summary, the present study verified the radiosensitizing effects of c-myc gene knockdown-induced G2/M phase arrest, which was achieved by intrinsic stimuli through the mitochondrial signaling pathway.
\end{abstract}

Correspondence to: Dr Fan He, The Affiliated Hangzhou First People's Hospital, Zhejiang University School of Medicine, 261 Huansha Road, Shangcheng, Hangzhou, Zhejiang 310006, P.R. China

E-mail: qq975137299@icloud.com

Key words: radiosensitizing, c-myc, G2/M phase arrest, osteosarcoma, mitochondrial

\section{Introduction}

A total of 3 out of 1,000,000 people are diagnosed with osteosarcoma, which is the most common primary malignant bone tumor in children and adolescents (1). Osteosarcoma typically occurs in the metaphysis of long bones such as the femur, tibia and humerus (2). Although cytotoxic neoadjuvant chemotherapy drugs including cisplatin, doxorubicin, methotrexate and ifosfamide combined with surgery and postoperative chemotherapy are feasible treatments for osteosarcoma, the survival rate has not increased significantly in the past decades $(3,4)$.

The focus of osteosarcoma treatment has been shifted from survival through limb-amputation to improvement of the quality of life through limb-salvage surgery (5). Radiotherapy can induce cell apoptosis by breaking DNA double strands to reduce the local recurrence rate (6). However, it is only used as an adjuvant treatment in patients who have received limb-salvage surgery as osteosarcoma is not sensitive to radiotherapy (7). Several studies have shown that radiotherapy can be used as an alternative surgical treatment for some staged patients $(8,9)$. After adjuvant chemotherapy, radiotherapy is effective in $56 \%$ of patients with limb tumors (10).

The proto-oncogene c-myc is a transformed member of the myc family. Approximately $20 \%$ of human cancers may be associated with c-myc overexpression (11). As a transcription activator, it regulates cell growth, differentiation, programmed cell death and apoptosis (12). C-myc-interacting zinc finger protein-1 (Miz-1) is a poly-Cys2His2 zinc finger (ZF) activator of cell cycle regulator genes, such as the cyclin-dependent kinase inhibitor p21 (13). Some studies have found that c-myc combined with zinc finger transcription factor Miz-1 can upregulate the expression of $\mathrm{p} 21$ by abolishing the interaction between Miz-1 and its co-activators, which activates G2/M phase transition, such as the cyclinB1/Cdc2 complex $(14,15)$. Hence, inhibiting c-myc gene expression can restrain tumor cell growth in the $\mathrm{G} 2 / \mathrm{M}$ phase $(16,17)$. Additionally, some studies have shown that tumors in the G2/M phase are more sensitive to radiotherapy $(18,19)$. Therefore, radiotherapy combined with downregulation of the c-myc gene could be a therapeutic strategy for human osteosarcoma. To the best of our knowledge, no research has been conducted to investigate 
the radiosensitizing effect of the c-myc gene on osteosarcoma. Therefore, the present study investigated the radiosensitizing effect of the c-myc gene and the sensitizing apoptosis pathway, in order to provide a more effective combination radiotherapy treatment for osteosarcoma.

\section{Materials and methods}

Comprehensive analysis. Genetic data (GSE126209) of the corresponding samples were downloaded from The Cancer Genome Atlas (TCGA) (https://www.cancer.gov/aboutnci/organization/ccg/research/structural-genomics/tcga) data portal. The differential expression data of genes were normalized and analyzed by edgeR, a Bioconductor package based on R 3.53 (https://www.r-project.org/). Kaplan-Meier survival analyses were utilized to assess the overall survival of patients with sarcoma who were classified into high-expression and low-expression groups based on the myc gene from the University of Alabama web portal (http://ualcan.path. uab.edu/) (20). Available TCGA survival data was used for Kaplan-Meier survival analysis the overall survival plots were generated. Functional protein association network of the myc gene was constructed using the STRING database (https://string-db.org/).

Reagents and antibodies. DMEM, Minimum Essential Medium (MEM), Roswell Park Memorial Institute (RPMI)-1640 Medium, FBS, penicillin, streptomycin, PBS and $0.25 \%$ trypsin were purchased from Gibco (Thermo Fisher Scientific, Inc.). Antibodies against caspase-3 (cat. no. 9662), cleaved caspase-3 (cat. no. 9661), poly (ADP-ribose) polymerase (PARP) (cat. no. 9532), cleaved PARP (cat. no. 5625), Bax (cat. no. 5023), Bid (cat. no. 2002), Bcl-2 (cat. no. 4223), Cdc2 (cat. no. 28439), cyclin B1 (cat. no. 12231), cyclin D1 (cat. no. 55506), p21 (cat. no. 2947) and GAPDH (cat. no. 5174) (all, 1:1,000) were purchased from Cell Signaling Technology, Inc. Primary antibody dilution buffer (cat. no. FD0040) was purchased from Fdbio Science.

Cell culture. hHOF1.19, MG63, HOS and U2OS cells from the Shanghai Cell Bank of the Chinese Academy of Sciences were tested for mycoplasma contamination. Cells were routinely cultured in a cell incubator $\left(37^{\circ} \mathrm{C} ; 5 \% \mathrm{CO}_{2}\right.$; Thermo Fisher Scientific, Inc.) in high-glucose DMEM supplemented with $100 \mu \mathrm{l} / \mathrm{ml}$ penicillin-streptomycin and $10 \% \mathrm{FBS}$.

Reverse transcription-quantitative PCR (RT-qPCR). RT-qPCR was performed to determine the expression of c-myc in hHOF1.19, MG63, HOS and U2OS cells. TRIzol ${ }^{\circledR}$ reagent (Invitrogen; Thermo Fisher Scientific, Inc.) was used to extract total RNA from the cells according to the manufacturer's instructions. PrimeScript ${ }^{\mathrm{TM}}$ RT Reagent kit (Takara Bio, Inc.) was used to reverse transcribe RNA to cDNA. The reaction conditions used for RT were as follows: Incubation at $37^{\circ} \mathrm{C}$ for $15 \mathrm{sec}$, followed by $85^{\circ} \mathrm{C}$ for $30 \mathrm{sec}$. C-myc levels were quantified using SYBR Premix Ex Taq (Takara Biotechnology Co., Ltd.) on an ABI 7500 Fast Sequence Detection System (Applied Biosystems; Thermo Fisher Scientific, Inc.). The following thermocycling conditions were used for the qPCR: Initial denaturation at $95^{\circ} \mathrm{C}$ for $1 \mathrm{~min}$, followed by 40 cycles of $95^{\circ} \mathrm{C}$ for $5 \mathrm{sec}$ and $60^{\circ} \mathrm{C}$ for $34 \mathrm{sec}$. GAPDH was used as the internal reference gene and the relative expression levels of c-myc in hFOB, MG63, U2OS and HOS osteosarcoma cells were analyzed using the $2^{-\Delta \Delta \mathrm{Cq}}$ method (21) The following primer pairs were used for the qPCR: c-myc forward, 5'-GTC AAGAGGCGAACACACAAC-3' and reverse, 3'-TTGGAC GGACAGGATGTATGC-5' and GAPDH forward, 5'-TGT TCGTCATGGGTGTGAAC-3' and reverse, 5'-ATGGCATGG ACTGTGGTCAT-3'.

Cell transfection. MG63 cells were seeded into six-well plates at a density of $2 \times 10^{5}$ cells/well. After reaching 70-90\% confluence, complete medium was replaced with MEM without FBS or penicillin-streptomycin. Subsequently, small interfering RNA (siRNA) targeting c-myc was transfected in MG63 cells using Lipofectamine ${ }^{\circledR} 2000$ (Invitrogen; Thermo Fisher Scientific, Inc.) at a concentration of $50 \mathrm{nM}$. After $6 \mathrm{~h}$, the medium was replaced with complete medium to continue cultivation. To identify the transfection efficiency of siRNA, transfected MG-63 cells were observed by fluorescence imaging and transfection efficiency was compared with non-transfected MG-63 cells. The siRNA inhibitor sequence was as follows: Forward, 5'-GGAAGAAAUCGAUGUUGU UTT-3' and reverse, 3'-AACAACAUCGAUUUCUUCCTT-5'. The si-negative control inhibitor sequence was as follows: Forward, 5'-UUCUCCGAACGUGUCACGUTT-3' and reverse, 3'-ACGUGACACGUUCGGAGAATT-5'.

Cell viability assay. A Cell Counting Kit-8 (CCK-8; MedChemExpress) assay was used to determine cell viability according to the manufacturer's instructions. Firstly, cells transfected with si-c-myc and si-negative control (NC) were seeded into 96 -well plates at a density of $5 \times 10^{3}$ cells/well. A total of $100 \mathrm{ml} \mathrm{CCK}-8$ solution mixed with incomplete MEM (1:10) was added into each well and cell viability was measured at 24, 48, 72 and $96 \mathrm{~h}$ on a MR7000 microplate reader (Dynatech) at $450 \mathrm{~nm}$ absorbance $30 \mathrm{~min}$ later.

Cell cycle analysis. Cells transfected with siRNA after 0, 24, 48, 72 and $96 \mathrm{~h}$ were digested and washed twice with PBS and then fixed with $75 \%$ ethanol at $-20^{\circ} \mathrm{C}$ overnight. Propidium iodide (PI; BD Biosciences) was added to cells and incubated for $15 \mathrm{~min}$. Cells cycle analysis was performed with a FACSCalibur flow cytometer (BD Biosciences) and data were analyzed with CellQuest software 3.1 (BD Biosciences).

Apoptosis analysis. The FITC Annexin V apoptosis Detection Kit I (BD Pharmingen; BD Biosciences) was used for apoptosis analysis. First, the cells were digested, washed with PBS and resuspended in 1X Binding Buffer. Subsequently, cells were transferred in $100 \mu \mathrm{l}$ resuspended mixture solution $\left(1 \times 10^{5}\right.$ cells) into a $5 \mathrm{ml}$ culture tube. A total of $5 \mu \mathrm{l} \mathrm{V}$-FITC and $5 \mu \mathrm{l}$ PI were added into the tube and incubated at room temperature for $15 \mathrm{~min}$. Finally, $400 \mu \mathrm{l} 1 \mathrm{X}$ Binding Buffer was added to each tube. Cell apoptosis analysis was performed with a FACSCalibur flow cytometer (BD Biosciences), and data were analyzed with CellQuest software 3.1 (BD Biosciences).

Clone formation assay. Cells in the logarithmic growth phase were seeded in a six-well plate with $200-800$ cells/well and 
incubated at $37^{\circ} \mathrm{C}$ for 2 weeks until visible colonies appeared in the wells. Following washing with PBS twice, a mixture of $0.1 \%$ crystal violet and $4 \%$ polymethanol was added to fix and stain for $30 \mathrm{~min}$ at $37^{\circ} \mathrm{C}$. The dye was washed away slowly with running water. Clones with $>50$ cells were counted under an optical microscope (magnification, x200).

Radiotherapy. MG63 cells transfected with si-NC and si-c-myc were seeded in a six-well plate with 200-800 cells/well and cultured in a $37^{\circ} \mathrm{C}$ and $5 \% \mathrm{CO}_{2}$ incubator for $24 \mathrm{~h}$. An X-ray instrument (Precision X-Ray, Inc.) was used to irradiate the cells at dose rates of 2, 4, 6 and 8 Gy. Subsequently, MG63 cells were cultured in the incubator for 10 days.

Fluorescence assays. Cell apoptosis was detected by fluorescence microscopy using DAPI reagent (Beyotime Institute of Biotechnology) for nuclear staining. In brief, cells fixed with $4 \%$ polymethanol were stained with DAPI and incubated in the dark for $15 \mathrm{~min}$ at $37^{\circ} \mathrm{C}$. After washing twice with PBS, cells were observed under a fluorescence microscope (magnification, x200) (Olympus Corporation) to identify nuclear fragmentation and chromatin condensation.

Western blot analysis. MG63 cells in six-well plates treated with si-NC, si-c-myc or radiotherapy were digested and lysed in RIPA lysis buffer containing protease inhibitor cocktail (Sigma-Aldrich; Merck KGaA). Protein concentration was measured using a BCA protein assay kit (Pierce; Thermo Fisher Scientific, Inc.) according to the manufacturer's instructions on a MR7000 microplate reader (Dynatech) at a wavelength of $570 \mathrm{~nm} 30 \mathrm{~min}$ later. Equal amounts of protein $(40 \mu \mathrm{g})$ were separated via SDS-PAGE (12\% polyacrylamide gels). Electrophoresis and membrane transfer were performed at $100 \mathrm{~V}$ for $1.5 \mathrm{~h}$ and $300 \mathrm{~mA}$ for $1 \mathrm{~h}$, respectively. Separated proteins were transferred to a PVDF membrane, blocked with 5\% non-fat milk in TBS-0.1\% Tween 20 (TBS-T) at $37^{\circ} \mathrm{C}$ for $1 \mathrm{~h}$ and then incubated in primary target antibodies (Cell Signaling Technology, Inc.) overnight at $4^{\circ} \mathrm{C}$. Following three washes with TBS-T, membranes were incubated with HRP anti-rabbit (cat. no. FD0128) or anti-mouse IgG (cat. no. FD0142) antibodies (Fdbio Science) diluted in $5 \%$ non-fat milk (1:5,000 working dilution) for $1 \mathrm{~h}$ at room temperature. Protein bands were visualized using the Westar Supernova kit (Cyanagen) and a molecular imager (Bio-Rad Laboratories, Inc.). Densitometric analysis was performed using Image 1.8 .0 (National Institutes of Health).

Statistical analysis. The data were expressed as mean \pm SD and analyzed by SPSS 17.0 (SPSS Inc.). The t-test was used to calculate the difference between two groups. One-way ANOVA to compare differences among three or more groups followed by Tukey's post hoc test. Tests were two-tailed and $\mathrm{P}<0.05$ was considered to indicate a statistically significant difference.

\section{Results}

Comprehensive analysis of the myc gene. Comprehensive analysis using a heat map with bidirectional hierarchical clustering of genes and RT-qPCR was conducted. It was found that myc was overexpressed in tumor samples compared with normal samples (Fig. 1A and B). Kaplan-Meier curve analysis of myc for overall survival showed that myc was negatively associated with patient overall survival (Fig. 1C). STRING database analysis showed that $\mathrm{G} 2 / \mathrm{M}$ cell cycle target proteins such as cdc2, p21 and cyclin B1 may be associated with the myc gene (Fig. 1D).

Relative c-myc gene expression in osteosarcoma and siRNA knockdown efficiency. To investigate the relative c-myc expression in osteosarcoma, RT-qPCR was performed in osteosarcoma cells HOS, MG63, U-2 and c-myc expression was compared against normal cartilage cells hHOF1.19 (Fig. 2A). C-myc was significantly overexpressed in MG-63 cells but not in U-2 and HOS cells. The present data demonstrated that the levels of c-myc were higher in MG-63 and U-2 tumor cells compared with hFOB1.19 cells, particularly in MG-63 cells. Thus, MG-63 cells were used for subsequent experiments. Subsequently, siRNA was transfected to downregulate c-myc expression in MG-63 osteosarcoma cells. The transfection efficiency of siRNA was observed using fluorescence imaging. As shown in Fig. 2B, $>80 \%$ of MG-63 cells expressed green fluorescence protein $48 \mathrm{~h}$ after transfection. The knockdown efficiency of si-c-myc was verified by RT-qPCR and western blotting. As shown in Fig. 2C and D, the expression levels of the c-myc gene was significantly decreased in MG-63 cells transfected with si-c-myc compared with the si-NC group.

c-myc knockdown inhibits the proliferation of osteosarcoma cells and induced caspase-dependent apoptosis via intrinsic pathways. To investigate the effects of c-myc on proliferation, MG63 cells were transfected with siRNA. Colony formation and cell viability assays were performed. The cell viability and colony formation assays showed that knockdown of the c-myc gene significantly inhibited the proliferation of osteosarcoma cells (Fig. 3A and B). To determine whether inhibition of cell growth could be attributed to apoptosis, DAPI staining and flow cytometry assay were performed. Fig. 3C and D showed that c-myc knockdown increased early and late apoptotic cell proportion, chromatin condensation and DNA fragmentation. Next, western blotting was performed to identify the pathways involved. As shown in Fig. 3E, knockdown of c-myc markedly increased the expression of Bax, cleaved PARP and cleaved caspase- 3 proteins and decreased the expression of c-myc, caspase-9, Bid, Bcl-2, caspase- 3 and PARP proteins.

c-myc knockdown induces $G 2 / M$ phase arrest by regulating cell cycle-regulated proteins. To determine whether knockdown of the c-myc gene inhibited cell proliferation by inducing cell cycle arrest, the present study examined the cell cycle distribution at $0,24,48,72$ and $96 \mathrm{~h}$ after si-c-myc transfection in MG-63 cells. As shown in Fig. 4A, c-myc knockdown increased $\mathrm{G} 2 / \mathrm{M}$ phase cell proportion and decreased $\mathrm{G} 0 / \mathrm{G} 1$ and $\mathrm{S}$ phases in MG-63 cells. The arrest rate reached the highest levels at $48 \mathrm{~h}$. The cell cycle-regulated proteins cyclin B1 and p21 was upregulated and Cdc2 and cyclin D1 were downregulated (Fig. 4B). The data suggested that knockdown of the c-myc gene induced $\mathrm{G} 2 / \mathrm{M}$ phase arrest by regulating $\mathrm{G} 2 / \mathrm{M}$ cell cycle target markers. 
A
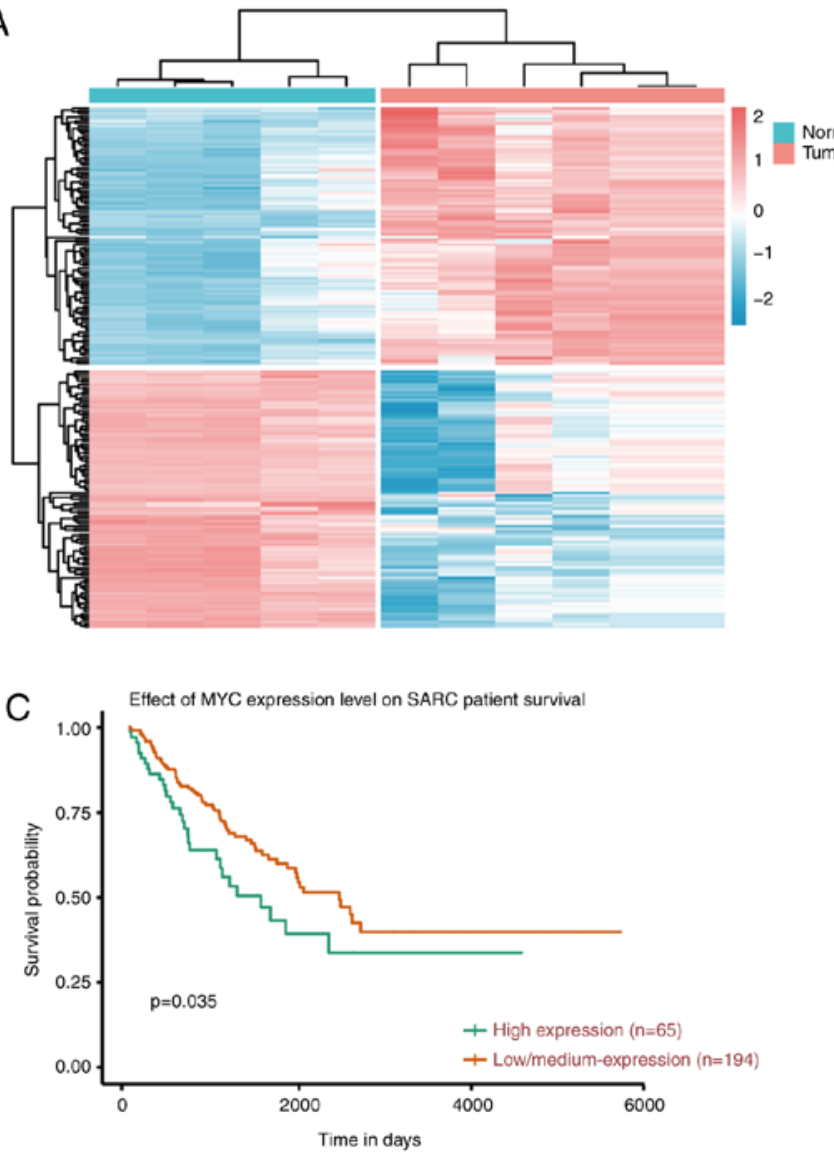

B

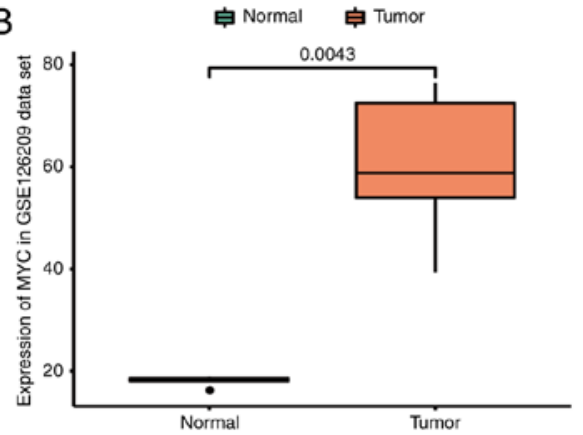

D

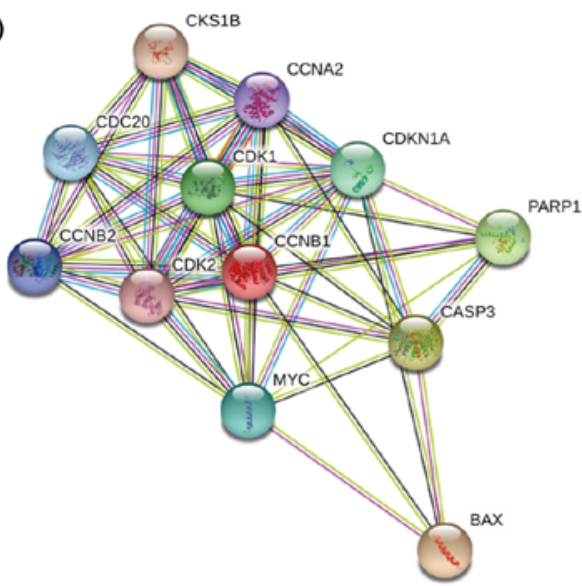

Figure 1. Comprehensive analysis of the myc gene. (A) Heat map with bidirectional hierarchical clustering of genes in osteosarcoma. The top 100 upregulated and 100 downregulated genes are shown in the heat map. (B) Validation of Myc expression by reverse transcription-quantitative PCR in osteosarcoma. The relative expression of Myc between tumor tissues and adjacent noncancerous tissues is shown. Data are presented as the mean \pm standard deviation. $\mathrm{n}=30$. (C) Kaplan-Meier curve analysis of myc expression for overall survival in patients with sarcoma. (D) Multiple protein assay of myc. SARC, sarcoma; CASP2, caspase 3; PARP1, poly (ADP-ribose) polymerase 1; CKS1B, cyclin-dependent kinases regulatory subunit 1; CCNA2, cyclin A2; CCNB1, G2/mitotic-specific cyclin-B1; CDC20, cell division cycle protein 20 homolog; CCNB2, G2/mitotic-specific cyclin-B2; CDKN1A, cyclin-dependent kinase inhibitor 1.
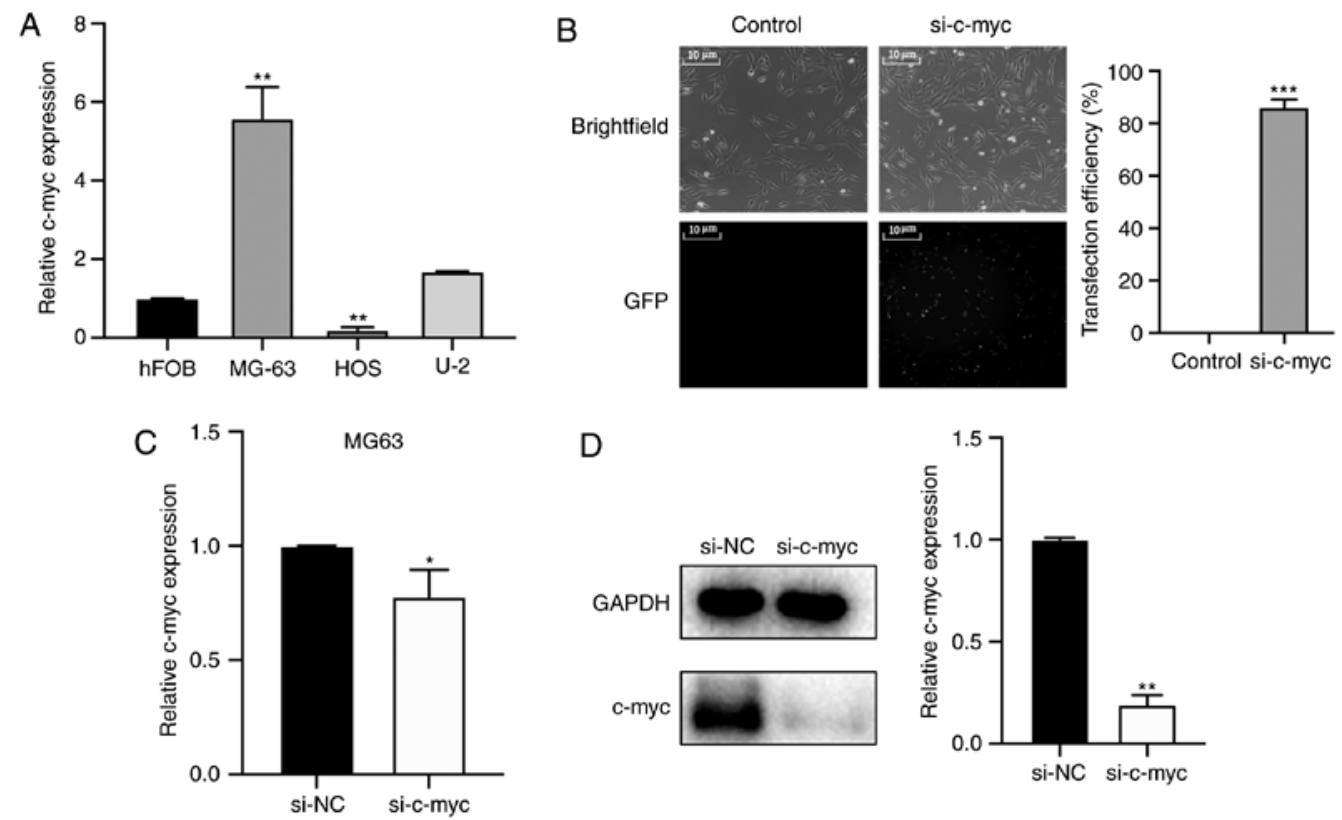

D

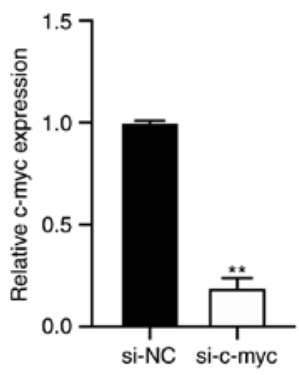

Figure 2. Relative c-myc gene expression in osteosarcoma and knockdown efficiency of siRNA. (A) Relative c-myc gene expression was determined in three osteosarcoma cell lines (MG63, HOS and U-2) and one osteoblastic cell line (hFOB 1.19) by RT-qPCR. ${ }^{* *} \mathrm{P}<0.01$ vs. hFOB1.19 cells. (B) Efficiency of siRNA transfection into MG63 cells was determined by fluorescence microscopy (magnification, x400). Knockdown efficiency of si-c-myc was confirmed by (C) RT-qPCR and (D) western blotting. ${ }^{*} \mathrm{P}<0.05,{ }^{* * *} \mathrm{P}<0.001$. Data are presented as the mean \pm standard deviation. RT-qPCR, reverse transcription-quantitative PCR; NC, negative control; GFP, green fluorescence protein; siRNA, small interfering RNA; si-c-myc, siRNA targeting c-myc. 

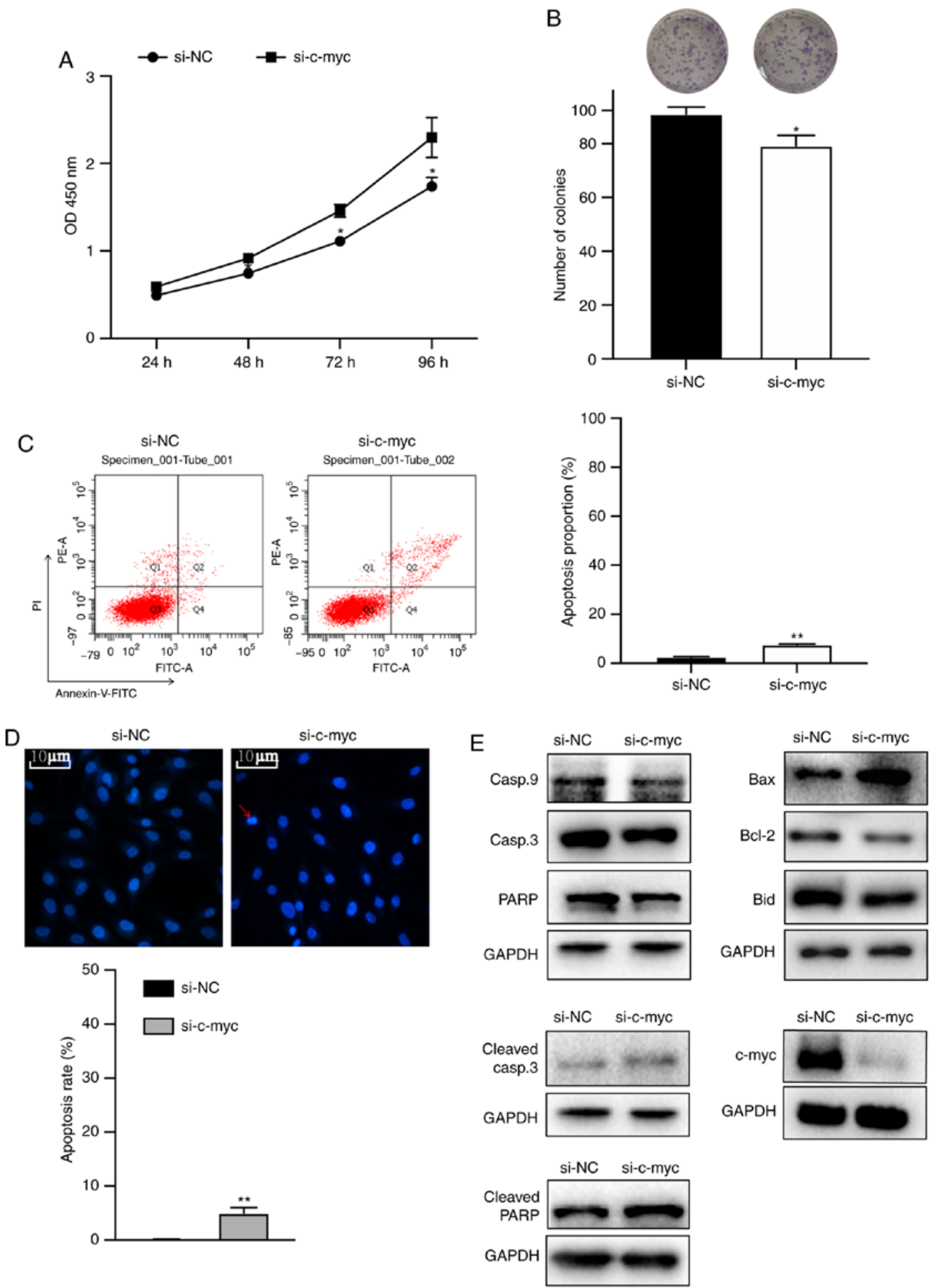

Figure 3. Knockdown of c-myc inhibits the proliferation of osteosarcoma cells and induces caspase-dependent apoptosis via intrinsic pathways. (A) Cell viability. (B) Number of colonies was evaluated in cells transfected with either si-c-myc or si-NC. The apoptosis rate was determined by (C) flow cytometry and (D) DAPI staining (magnification, $\mathrm{x} 400$ ) and apoptotic cells are marked by red arrows. (E) Caspase-dependent apoptosis through intrinsic pathways was determined by western blotting. " $\mathrm{P}<0.05$ and ${ }^{* *} \mathrm{P}<0.01$ vs. si-NC. si, small interfering RNA; OD, optical density; PI, propidium iodide; NC, negative control; FITC, fluorescein isothiocyanate; Casp, caspase.

Assessing the radiosensitivity of MG-63 cells. MG63 cells were irradiated at $0,2,4,6 \mathrm{ND} 8 \mathrm{~Gy}$ to determine the radiosensitivity. As shown in Fig. 4C, the colony-forming efficiency was $46.3,22.2,2.8,0.6$ and $0.0 \%$, respectively. Cell survival rates were significantly reduced in a dose-dependent manner.
Radiosensitizing effects of c-myc knockdown is determined by inducing G2/M phase arrest. Radiosensitivity was investigated by reducing c-myc gene expression via inducing G2/M phase arrest. Fig. 5A shows that apoptotic chromatin condensation and DNA fragmentation were significantly increased in the si-c-myc +2 Gy group compared with other 

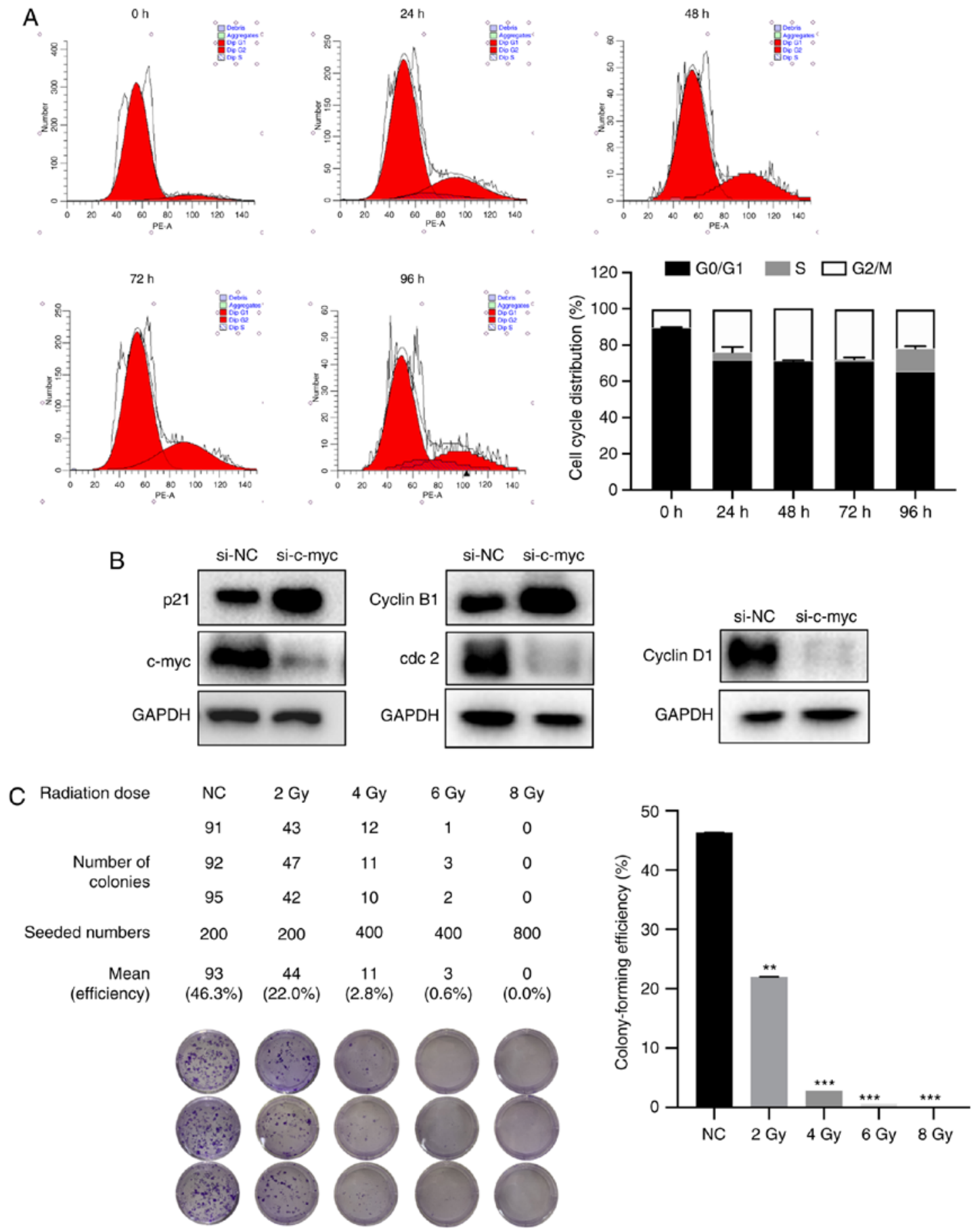

Figure 4. Knockdown of c-myc induces G2/M phase arrest by regulating cell cycle-regulated proteins and the radiosensitivity of MG-63 cells is assessed. (A) Cell cycle distribution was determined by PI staining and flow cytometry analysis. (B) Western blotting showing that G2/M phase arrest was activated through cell cycle-regulated proteins. (C) MG63 cells were irradiated at $0,2,4,6$ and 8 Gy and colony formation assays were performed to assess the radiosensitivity. ${ }^{* * *} \mathrm{P}<0.01$ and ${ }^{* * * *} \mathrm{P}<0.001$ vs. NC. $\mathrm{NC}$, negative control; si, small interfering RNA.

groups. The mean numbers of colonies formed were $92,79,52$ and 3, respectively, in si-NC, si-c-myc, 2 Gy and si-c-myc + 2 Gy groups with a seeding density of 200 cells/well. The colony-forming efficiency was significantly reduced in the 2 Gy group with c-myc knockdown group (Fig. 5B). The knockdown efficiency of si-c-myc was verified by RT-qPCR (Fig. 5C) and the expression levels the of c-myc gene was significantly decreased in si-c-myc and si-c-myc +2 Gy groups. Western blot analysis showed that the cell cycle-regulated proteins cyclin B1 and p21 were upregulated and Cdc2 and cyclin D1 was downregulated in both si-c-myc and si-c-myc +2 Gy groups. The apoptosis-related proteins caspase-9, c-myc, cdc2, cyclin D1, Bid, Bcl-2, caspase-3 and PARP were decreased while p21, cyclin B1, Bax, cleaved PARP and cleaved caspase- 3 were increased in the si-c-myc + 2 Gy group (Fig. 5D). These results suggested that downregulating c-myc expression induced the radiosensitizing effects involved in G2/M phase arrest, which increased the apoptosis of osteosarcoma cells by intrinsic stimuli via the mitochondrial signaling pathway (Fig. 6). 

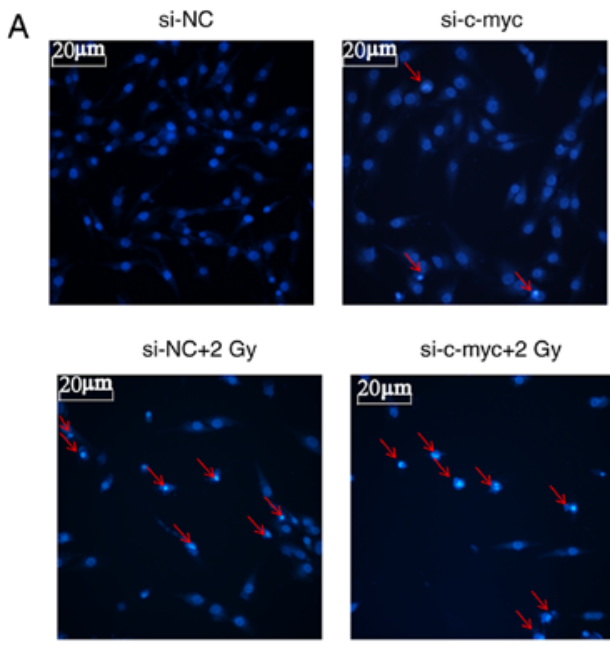

si-c-myc+2 Gy
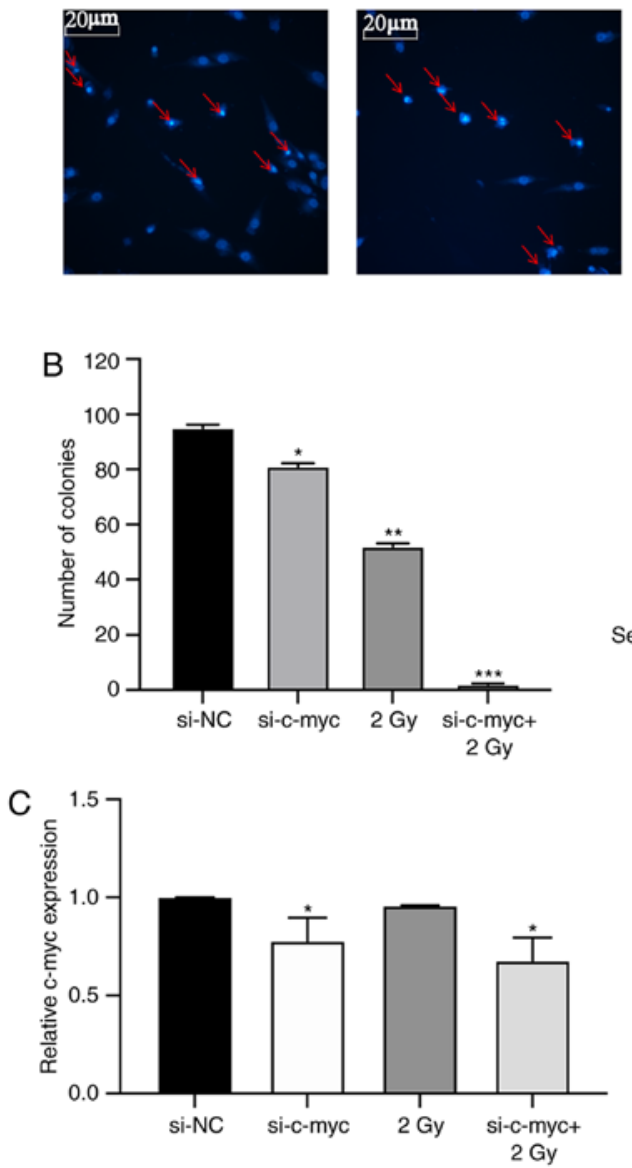

D

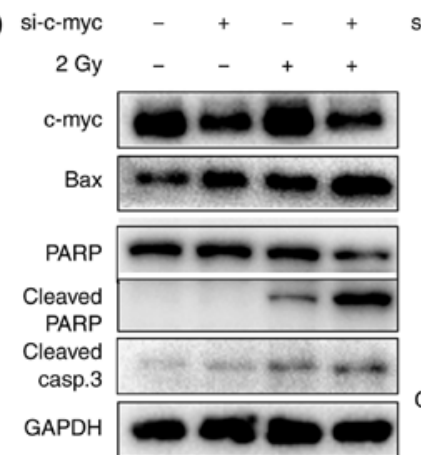

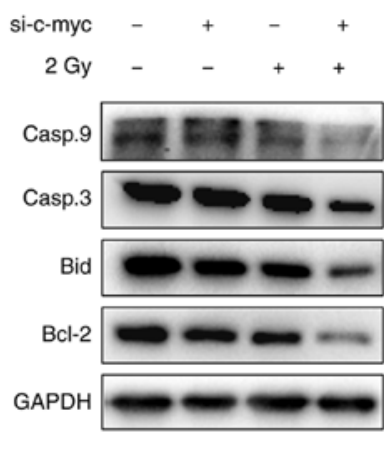
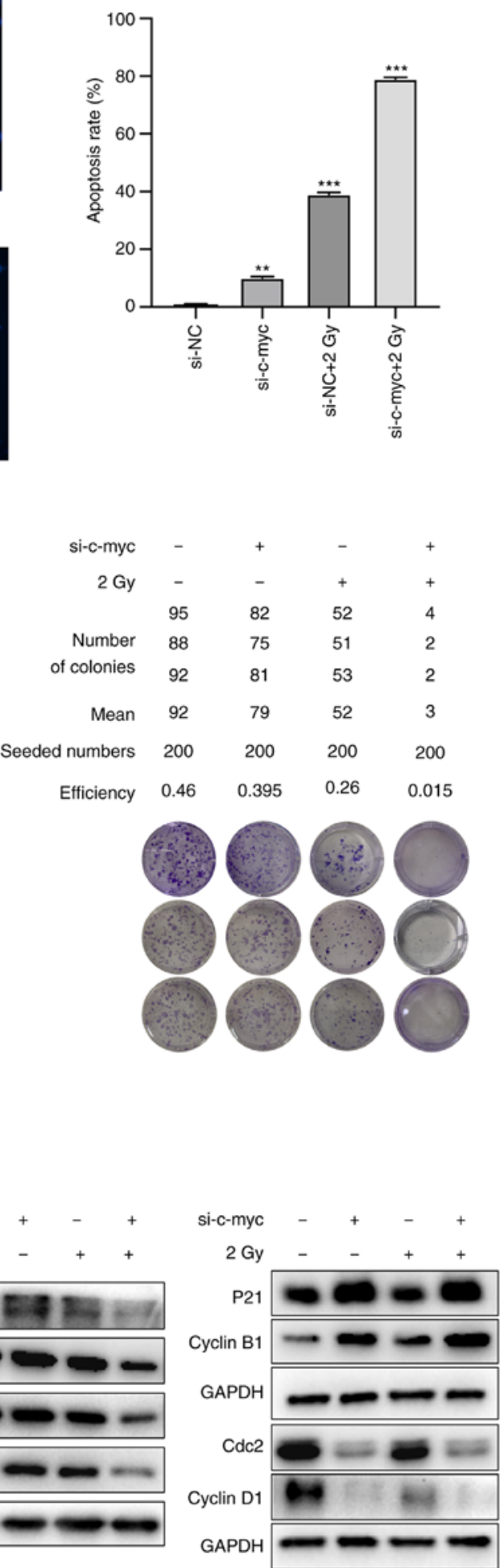

Figure 5. Radiosensitizing effects of c-myc gene knockdown by inducing G2/M phase arrest. (A) The apoptosis rate was determined by DAPI staining (magnification, x200) and apoptotic cells are marked by red arrows. (B) Radiosensitizing effects of c-myc gene knockdown was determined by colony formation assays. (C) Knockdown efficiency of si-c-myc was confirmed by reverse transcription-quantitative PCR. (D) Apoptosis of osteosarcoma cells by intrinsic stimuli via the mitochondrial signaling pathway was determined by western blotting. Casp, caspase.; si, small interfering RNA; NC, negative control. * $<0.05$, ${ }^{* *} \mathrm{P}<0.01,{ }^{* * *} \mathrm{P}<0.001$.

\section{Discussion}

Osteosarcoma is insensitive to radiotherapy $(22,23)$. Some studies have shown that tumor cells in the G2/M phase have good sensitivity of radiotherapy (24-26). Inhibiting c-myc expression can effectively suppress the proliferation of tumor cells and induce $\mathrm{G} 2 / \mathrm{M}$ phase arrest $(27,28)$ as well as apoptosis of sarcoma cells $(18,29)$. The present study aimed to assess 


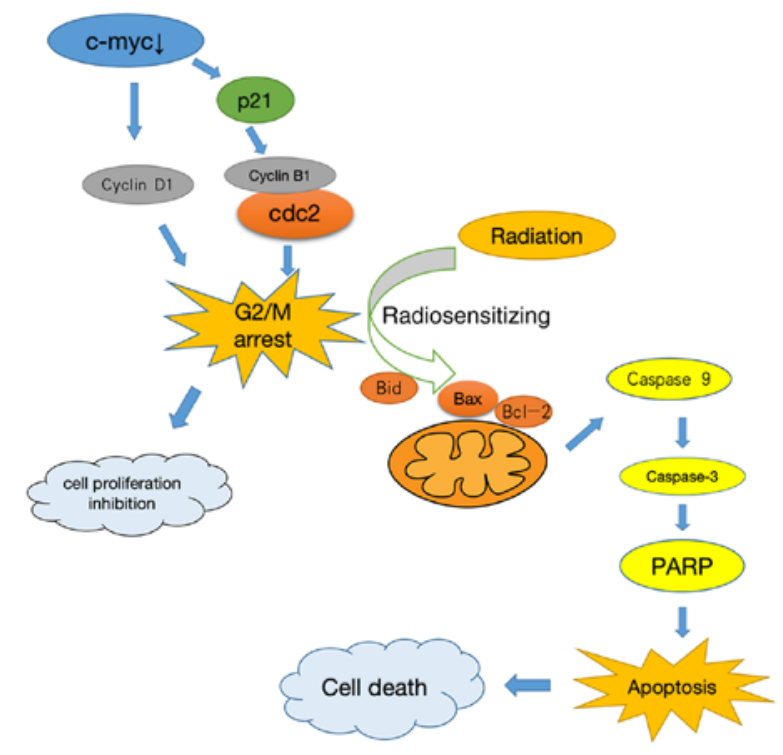

Figure 6. Schematic diagram of the pathways in which radiosensitizing effects of c-myc gene knockdown induced G2/M phase arrest by intrinsic stimuli through the mitochondrial signaling pathway. PARP, poly (ADP-ribose) polymerase.

the radiosensitizing effects of c-myc knockdown-induced G2/M phase arrest. The present study showed that downregulating c-myc significantly inhibited the proliferation of osteosarcoma cells and induced G2/M phase arrest. The combination of radiotherapy and c-myc inhibition resulted in a significantly higher apoptosis rate of osteosarcoma cells compared with using either therapy alone.

Previous analysis showed that the myc gene was overexpressed in osteosarcoma and negatively associated with patients' overall survival $(20,30)$. The present study demonstrated that the c-myc gene was overexpressed in MG63 osteosarcoma cells compared to osteoblasts. Tumor proliferation was significantly inhibited after inhibiting the expression of the c-myc gene in osteosarcoma cells. The G2/M phase has become a key cell cycle target marker for the inhibition of tumor proliferation $(31,32)$. During the initiation of the $\mathrm{M}$ phase, Cdc25 binds to proliferating cell nuclear antigen (PCNA) to catalyze the dephosphorylation of Cdc2 Y14/Y15, which activates the cyclin $\mathrm{B} 1 / \mathrm{Cdc} 2$ complex and subsequently cell mitosis. Therefore, the cyclin B1/Cdc2 complex plays a key role in inducing cell G2/M phase transition (33). C-myc and zinc finger transcription factor Miz-1 can inhibit cell cycle transcription factors, such as p21 (34). P21, the inhibitor of cdc2, can form a quaternary complex with $\mathrm{Cdc} 2$, cyclinB1 and PCNA, then competitively inhibits cdc 25 binding to PCNA and blocks cdc25 from catalyzing the cdc2 dephosphorylation (35). The present study identified that c-myc gene downregulation could induce p21 protein upregulation with the increase of $\mathrm{G} 2 / \mathrm{M}$ phase-associated protein cyclin B1 and the decrease of cdc2 protein, which leads to $\mathrm{G} 2 / \mathrm{M}$ phase arrest and inhibition of osteosarcoma cell proliferation.

To further determine whether cell cycle arrest was time-dependent, cell cycle distribution tests were performed at five time points $(0,24,48,72$ and $96 \mathrm{~h})$. The present study found that the cycle arrest was time-dependent: It peaked at $48 \mathrm{~h}$ and the arrest capacity of the $\mathrm{G} 2 / \mathrm{M}$ phase gradually decreased. Studies have also shown that c-myc is most effective in blocking tumor growth in $48 \mathrm{~h}$ (26). Radiotherapy performed at 0,2, 4, 6 and 8 Gy doses showed that the cell growth inhibition rate was $\sim 50 \%$ at $2 \mathrm{~Gy}$, similar to the result of a previous report (36).

Radiotherapy induces cell apoptosis by damaging DNA double strands and inhibiting cell cycle checkpoint activation (37). A previous study found that radiation sensitivity is highly correlated with cells G2/M phase (38). The present study hypothesized that inducing $\mathrm{G} 2 / \mathrm{M}$ phase arrest with drugs will increase the sensitivity of the cells to radiotherapy. Therefore, radiotherapy was performed on c-myc knockdown cells and verified the radiosensitizing effects of $c$-myc gene knockdown-induced G2/M phase arrest and the activation of mitochondrial-mediated apoptosis pathway in this process.

In summary, the present study revealed that inhibiting c-myc gene expression combined with radiotherapy could significantly increase the apoptosis rate of osteosarcoma cells. The present study verified the radiosensitizing effects of c-myc gene knockdown-induced $\mathrm{G} 2 / \mathrm{M}$ phase arrest, which was achieved by intrinsic stimuli via the mitochondrial signaling pathway. The results of the present study may provide an effective and novel therapeutic strategy for radiotherapy of osteosarcoma.

\section{Acknowledgements}

Not applicable.

\section{Funding}

This research was supported by the Agricultural and Social Development Research Independent Application Project of Hangzhou City (grant no. 20191203B88).

\section{Availability of data and materials}

The datasets used and/or analyzed during the current study are available from the corresponding author on reasonable request.

\section{Authors' contributions}

YF conceived and designed the study and wrote the manuscript. LZ searched the database and reviewed studies. TX and $\mathrm{XJ}$ performed data analysis and prepared the initial draft of the manuscript. FH participated in interpretation of data, helped in drafting the manuscript and critically reviewed the manuscript. All authors read and approved the final manuscript.

\section{Ethics approval and consent to participate}

Not applicable.

\section{Patient consent for publication}

Not applicable.

\section{Competing interests}

The authors declare that they have no competing interests. 


\section{References}

1. Kansara M, Teng MW, Smyth MJ and Thomas DM: Translational biology of osteosarcoma. Nat Rev Cancer 14: 722-735, 2014.

2. Kager L, Tamamyan G and Bielack S: Novel insights and therapeutic interventions for pediatric osteosarcoma. Future Oncol 13: 357-368, 2016.

3. Kelleher FC and O'Sullivan H: Monocytes, macrophages, and osteoclasts in osteosarcoma. J Adolesc Young Adult Oncol 6 : 396-405, 2017.

4. Ferrari S, Mercuri M and Bacci G: Comment on 'Prognostic factors in high-grade osteosarcoma of the extremities or trunk: An analysis of 1,702 patients treated on neoadjuvant Cooperative Osteosarcoma Study Group protocols'. J Clin Oncol 20: 2910-2911, 2002.

5. Bishop MW, Janeway KA and Gorlick R: Future directions in the treatment of osteosarcoma. Curr Opin Pediatr 28: 26-33, 2016.

6. Bugris V, Harmat V, Ferenc G, Brockhauser S, Carmichael I and Garman EF: Radiation-damage investigation of a DNA 16-mer. J Synchrotron Radiat 26: 998-1009, 2019.

7. Li QC, Xu H, Wang X, Wang T and Wu J: miR-34a increases cisplatin sensitivity of osteosarcoma cells in vitro through up-regulation of c-Myc and Bim signal. Cancer Biomark 21: 135-144, 2017.

8. Macaeva E, Saeys Y, Tabury K, Janssen A, Michaux A, Benotmane MA, De Vos WH, Baatout S and Quintens R: Radiation-induced alternative transcription and splicing events and their applicability to practical biodosimetry. Sci Rep 6: 19251, 2016.

9. Cruse MJ, Kucharik CJ and Norman JM: Using a simple apparatus to measure direct and diffuse photosynthetically active radiation at remote locations. PLoS One 10: e0115633, 2015.

10. Li S, Hu T, Yuan T, Cheng D and Yang Q: Nucleoside diphosphate kinase B promotes osteosarcoma proliferation through c-Myc. Cancer Biol Ther 19: 565-572, 2018.

11. Machak GN, Tkachev SI, Solovyev YN, Sinyukov PA, Ivanov SM, Kochergina NV, Ryjkov AD, Tepliakov VV, Bokhian BY and Glebovskaya VV: Neoadjuvant chemotherapy and local radiotherapy for high-grade osteosarcoma of the extremities. Mayo Clin Proc 78: 147-155, 2003.

12. Cartee L, Vrana JA, Wang Z, Park JS, Birrer M, Fisher PB, Grant $S$ and Dent P: Inhibition of the mitogen activated protein kinase pathway potentiates radiation-induced cell killing via cell cycle arrest at the $\mathrm{G} 2 / \mathrm{M}$ transition and independently of increased signaling by the JNK/c-Jun pathway. Int J Oncol 16: 413-422, 2000

13. Noh HJ, Koh DI, Lee KO, Jeon BN, Kim MK, Snead ML and Hur MW: Role of MIZ-1 in AMELX gene expression. Biochem Biophys Rep 8: 340-345, 2016.

14. Bédard M, Maltais L, Montagne M and Lavigne P: Miz-1 and Max compete to engage c-Myc: Implication for the mechanism of inhibition of c-Myc transcriptional activity by Miz-1. Proteins 85 : 199-206, 2017.

15. Licchesi JD, Van Neste L, Tiwari VK, Cope L, Lin X, Baylin SB and Herman JG: Transcriptional regulation of Wnt inhibitory factor-1 by Miz-1/c-Myc. Oncogene 29: 5923-5934, 2010.

16. Concin N, Stimpfl M, Zeillinger C, Wolff U, Hefler L, Sedlak J, Leodolter S and Zeillinger R: Role of p53 in G2/M cell cycle arrest and apoptosis in response to gamma-irradiation in ovarian carcinoma cell lines. Int J Oncol 22: 51-57, 2003.

17. Suen DF, Norris KL and Youle RJ: Mitochondrial dynamics and apoptosis. Genes Dev 22: 1577-1590, 2008.

18. Chen BJ, Wu YL, Tanaka Y and Zhang W: Small molecules targeting c-Myc oncogene: Promising Anti-cancer therapeutics. Int J Biol Sci 10: 1084-1096, 2014.

19. Lee JA, Paik EK, Seo J, Kim DH, Lim JS, Yoo JY and Kim MS Radiotherapy and gemcitabine-docetaxel chemotherapy in children and adolescents with unresectable recurrent or refractory osteosarcoma. Jpn J Clin Oncol 46: 138-143, 2015.
20. Chandrashekar DS, Bashel B, Balasubramanya SAH, Creighton CJ, Ponce-Rodriguez I, Chakravarthi BVSK and Varambally S: UALCAN: A portal for facilitating tumor subgroup gene expression and survival analyses. Neoplasia 19: 649-658, 2017.

21. Livak KJ and Schmittgen TD: Analysis of relative gene expression data using real-time quantitative PCR and the 2(-Delta Delta C(T)) method. Methods 25: 402-408, 2001

22. Unni KK and Dahlin DC: Osteosarcoma: Pathology and classification. Semin Roentgenol 24: 143-152, 1989.

23. Kim E, Kim MS, Lee KH, Sai S, Jeong YK, Koh JS and Kong CB: Effect of low- and high-linear energy transfer radiation on in vitro and orthotopic in vivo models of osteosarcoma by activation of caspase-3 and -9. Int J Oncol 51: 1124-1134, 2017.

24. Miyata H, Doki Y, Yamamoto $\mathrm{H}$, Kishi $\mathrm{K}$, Takemoto $\mathrm{H}$, Fujiwara Y, Yasuda T, Yano M, Inoue M, Shiozaki H, et al: Overexpression of CDC25B overrides radiation-induced G2-M arrest and results in increased apoptosis in esophageal cancer cells. Cancer Res 61: 3188-3193, 2001.

25. Fei H, Zhou Y, Li R, Yang M, Ma J and Wang F: HBXIP, a binding protein of $\mathrm{HBx}$, regulates maintenance of the $\mathrm{G} 2 / \mathrm{M}$ phase checkpoint induced by DNA damage and enhances sensitivity to doxorubicin-induced cytotoxicity. Cell Cycle 16: 468-476, 2017.

26. Li YX, Weber-Johnson K, Sun LQ, Paschoud N, Mirimanoff RO and Coucke PA: Effect of pentoxifylline on radiation-induced G2-phase delay and radiosensitivity of human colon and cervical cancer cells. Radiat Res 149: 338-342, 1998.

27. Cui F, Hou J, Huang C, Sun X, Zeng Y, Cheng H, Wang H and Li C: C-Myc regulates radiation-induced G2/M cell cycle arrest and cell death in human cervical cancer cells. J Obstet Gynaecol Res 43: 729-735, 2017.

28. Yang Y, Xue K, Li Z, Zheng W, Dong W, Song J, Sun S, Ma T and $\mathrm{Li} \mathrm{W}$ : c-Myc regulates the CDK1/cyclin B1 dependent-G2/M cell cycle progression by histone $\mathrm{H} 4$ acetylation in Raji cells. Int J Mol Med 41: 3366-3378, 2018.

29. Shang Y: LncRNA THOR acts as a retinoblastoma promoter through enhancing the combination of c-myc mRNA and IGF2BP1 protein. Biomed Pharmacother 106: 1243-1249, 2018.

30. Szklarczyk D, Gable AL, Lyon D, Junge A, Wyder S, Huerta-Cepas J, Simonovic M, Doncheva NT, Morris JH, Bork P, et al: STRING v11: Protein-protein association networks with increased coverage, supporting functional discovery in genome-wide experimental datasets. Nucleic Acids Res 47: D607-D613, 2019.

31. Group NP: Translocations involving c-myc and c-myc function. Oncogene 20: 5595-5610, 2001

32. Androutsopoulos V and Spandidos D: Anticancer pyridines induce $\mathrm{G} 2 / \mathrm{M}$ arrest and apoptosis via p53 and JNK upregulation in liver and breast cancer cells. Oncol Rep 39: 519-524, 2018.

33. Nurse P: Universal control mechanism regulating onset of M-phase. Nature 344: 503-508, 1990.

34. Charrier-Savournin FB, Château MT, Gire V, Sedivy J, Piette J and Dulic V: p21-mediated nuclear retention of Cyclin B1-Cdk1 in response to Genotoxic Stress. Molr Biol Cell 15: 3965-3976, 2004.

35. Dang C: MYC on the path to cancer. Cell 149: 22-35, 2012.

36. Zhang H, Zhang C and Wu D: Activation of insulin-like growth factor 1 receptor regulates the radiation-induced lung cancer cell apoptosis. Immunobiology 220: 1136-1140, 2015.

37. Speidel D: Transcription-independent p53 apoptosis: An alternative route to death. Trends in Cell Biology 20: 14-24, 2010.

38. Chen W, Liu Q, Fu B, Liu K and Jiang W: Overexpression of GRIM-19 accelerates radiation-induced osteosarcoma cells apoptosis by p53 stabilization. Life Sci 208: 232-238, 2018.

This work is licensed under a Creative Commons Attribution-NonCommercial-NoDerivatives 4.0 International (CC BY-NC-ND 4.0) License. 